\title{
Growth hormone for short children - whom should we be treating and why?
}

CJ Kelnar

Professor of Paediatric Endocrinology, University of Edinburgh, Edinburgh, UK

TITLE Impact of growth hormone therapy on adult height of children with idiopathic short stature: systematic review

AUTHORS: A Deodati, S Cianfarani

JOURNAL BMJ 20II; 342:c7157. http://dx.doi.org/I0.1136/bmj.c7/57

DECLARATION OF INTERESTS Professor Kelnar receives honoraria for speaking at meetings sponsored by, and has in the past received research grants from, growth hormone manufacturers. He has also been a member of advisory boards for growth hormone manufacturers.

\author{
Correspondence to CJ Kelnar \\ Professor of Paediatric \\ Endocrinology, University of \\ Edinburgh, 20 Sylvan Place, \\ Edinburgh EH9 IUW, UK
}

tel. +44 (0) I3I 5360611 e-mail chris@kelnar.com

\section{SUMMARY}

The objective of this paper was to determine systematically the impact of growth hormone $(\mathrm{GH})$ therapy on adult height of children with (so-called) 'idiopathic short stature' (ISS) using the Cochrane Central Register of Controlled Trials, Medline, and the bibliographic references from retrieved articles of randomised controlled trials (RCTs) and non-RCTs from 1985 to April 2010. Inclusion criteria were initial short stature (defined as height $>2$ standard deviation [SD] below the mean), peak growth hormone responses $>10$ micrograms per litre ( $\mu \mathrm{g} / \mathrm{L})$, prepuberty, no previous growth hormone therapy, and no comorbid conditions that would impair growth. Data extracted were adult height and overall gain in height from baseline measurement in childhood.

Three RCTs (II 5 children) met the inclusion criteria. The adult height of the GH treated children exceeded that of the controls by $0.65 \mathrm{SD}$ score $(\sim 4 \mathrm{~cm})$. The mean height gain in treated children was I.2 SD score compared with 0.34 SD score in untreated children. A difference of $\sim 1.2 \mathrm{~cm}$ in adult height was observed between two $\mathrm{GH}$ dose regimens. In the seven nonRCTs, adult height of the GH-treated group exceeded that of controls by $0.45 \mathrm{SD}$ score $(\sim 3 \mathrm{~cm})$.

The authors conclude that I) $\mathrm{GH}$ therapy in children with ISS seems effective in partially reducing the deficit in height as adults, although less so than in other conditions for which $\mathrm{GH}$ is licensed; treated individuals remain relatively short compared with normal height peers. 2) Individual responses to therapy are highly variable; further studies are needed to identify responders. 3) High quality evidence from long-term RCTs of GH therapy that continue until adult height is necessary to determine the ideal dosage and long-term safety.

\section{OPINION}

Short stature is not a disease and 'normal' is not 'average'. Making someone taller, even if achievable, is not an end in itself. While $\mathrm{GH}$ therapy for clearly $\mathrm{GH}$-deficient short children is well accepted, treatment of ISS remains controversial. .2 However 'normality', 'GH insufficiency', and 'ISS' remain difficult to define due to the poor efficiency, sensitivity and specificity of $\mathrm{GH}$ stimulation tests. Because something is measurable, or is thought to be (e.g. a GH level in response to a particular stimulation test) does not render the outcomes clinically relevant. ${ }^{3,4}$ Equally, adult height is not a validated proxy for psychological contentment or 'quality of life' (QoL). Sometimes what is most important is most difficult to measure.

Statistically significant outcomes, e.g. (slightly) increased adult height, must be evaluated in terms of clinical benefit - the presence and potential for alleviation of short stature-related distress is crucial. ${ }^{.}$Many pronouncements relating to the psychosocial consequences of short stature are based on children referred for investigation, who are more likely to have other pathology or greater problems with psychosocial adaptation (or parents who perceive that they will). Evidence suggests little effect on psychological functioning from being shorter than average in children, adolescents or adults..$^{6-8}$

Studies on the pharmacological use of GH in ISS must be designed not simply to determine the most effective strategy to improve adult height, but also to balance the effect of height gain on psychological health and social wellbeing against effects on QoL of daily injections, potential short- and long-term adverse effects of $\mathrm{GH}$ therapy (including unmet expectations) and treatment costs. Long-term safety data (including in adults treated with GH in childhood only) are necessary. 
Clinical medicine is a holistic attempt to provide the best care for patients. ${ }^{9}$ A clinician's knowledge may be biased (belief versus knowledge), families' and patients' expectations may be unrealistic, and a 'worthwhile' outcome may be difficult to define. ${ }^{10-12}$ Unless broader questions are raised as to what constitutes benefit, ${ }^{6}$ the

\section{REFERENCES}

I Haverkamp F, Ranke MB. The ethical dilemma of growth hormone treatment of short stature: a scientific theoretical approach. Horm Res 1999; 5I:30 I-4. http://dx.doi.org//0.I I59/0000234I7

2 Kelnar C], Albertsson-Wikland K, Hintz RL et al. Should we treat children with idiopathic short stature? Horm Res 1999; 52:150-7. http://dx.doi.org/I0.I I59/000023452

3 Carroll L. Through the looking-glass, and what Alice found there. London: Macmillan and Co; I87I.

4 Dawkins R. A devil's chaplain. Selected essays. London:Weidenfeld and Nicolson; 2003

5 Kelnar CJ. Pride and prejudice: stature in perspective. Acta Paediatr ScandSuppl I990;370:5-15.http://dx.doi.org/I0. I I I I/j.I65I-2227.1990. tbl I662.x

6 Sandberg DE, Brook AE, Campos SP. Short stature: a psychosocial burden requiring growth hormone therapy? Pediatrics 1994; 94:832-40.

7 Downie AB, Mulligan J, Stratford RJ et al.Are short normal children at a disadvantage? The Wessex growth study. BMJ 1997; 314:97-100. http://dx.doi.org//0.I I36/bmj.3|4.7074.97 debate in treating short children will remain at the 'centimetres gained' (or even 'predicted to be gained') level, and properly designed studies to address important wider safety issues and psychological and QoL outcomes will not take place.
8 Rekers-Mombarg LT, Busschbach J], Massa GG et al. Quality of life of young adults with idiopathic short stature: effect of growth hormone treatment. Dutch Growth Hormone Working Group. Acta Paediatr I998; 87:865-70. http://dx.doi.org/I0. I I I I/j.I65I-2227.I998.tb0 I553.x

9 Asher R. Straight and crooked thinking in medicine. BMJ 1954; 2:460-2. http://dx.doi.org//0.1 I36/bmj.2.4885.460

10 Kelnar CJ. Evidence-based child health: SIGN and NICE. Arch Dis Child Educ Pract Ed 2008; 93:190-8.

II Kelnar CJ. The evidence base for growth hormone effectiveness in children.EndocrDev20 I0; 18:23-39.http://dx.doi.org/I0.I I59/0003 I6I 25

12 Kelnar CJ. Idiopathic short stature: considerations from the clinic the viewpoint of the paediatric endocrinologist. Horm Res Paediatr 201 I; 76 Suppl 3:35-7. http://dx.doi.org//0.1 159/000330I54

\section{UPCOMING SYMPOSIA}

Care of the Elderly (Edinburgh)

The Genomics Revolution (Edinburgh)

Oncology (Edinburgh)

Rheumatology (Edinburgh)

Paediatrics (RCPE/RCPCH joint symposium)

Neurology (Edinburgh)

Diabetes (Edinburgh)

Renal Medicine (Edinburgh)

Book online at http://events.rcpe.ac.uk

Live links are available to most symposia
All symposia are held at the Royal College of Physicians of Edinburgh unless otherwise stated.

Programme details at: http://events.rcpe.ac.uk or contact the Symposium Co-ordinator: Email: e.strawn@rcpe.ac.uk

\section{Webstreamed lectures}

If you are unable to attend symposia at the College in Edinburgh, selected lectures from all symposia are available to view and listen to in the Online Education Portal. http://learning.rcpe.ac.uk

There are currently more than 100 lectures covering all the medical specialties and a range of generic topics. 